\title{
O regime de chuvas em Pesqueira
}

FREDERICO PIMENTTEL GOMES

IZAIAS RANGEL NOGUEIRA

E. S. A. "Luiz de Queiroz" 


\section{INTRODUÇÃO}

Pesqueira é uma pequena cidade do Agreste pernambucano, situada no planalto da Borborema, famosa pelas suas indústrias de goiabada e de extrato de tomate. $\mathrm{E}$ fói a pedido do Eng. ${ }^{\circ}$ Agr. ${ }^{\circ}$ Moacyr Britto de Freitas, chefe da mais famosa dessas indústrias, a Fábrica Peixe, que fizemos um estudo estatístico dos dados pluviométricos de Pesqueira, num período de 48 anos, principalmente tendo em vista verificar se há tendência secular de redução ou aumento do total de chuvas.

\section{MATERIAL E MÉTODOS}

Os dados analisados são os que constam do Quadro n.0 1, e abrangem um período de 48 anos, de 1910 a 1957. O método de análise usado foi o dos polinômios ortogonais, o mais indicado, șem dúvida, para êste caso.

Tentaram-se obter componentes do $1 .^{\circ}$ ao $4 .^{\circ}$ grau.

Chuvas anuais em mm em Pesqueira (Pe) de 1910 a 1957

\begin{tabular}{c|c|c|c|c|c}
\hline Anos & $\begin{array}{c}\text { Chuvas } \\
\text { em mm }\end{array}$ & Anos & $\begin{array}{c}\text { Chuvas } \\
\text { em mm }\end{array}$ & Anos & $\begin{array}{c}\text { Chuvas } \\
\text { em mm }\end{array}$ \\
\hline \hline 1910 & 860,9 & 1926 & 1056,1 & 1942 & 545,4 \\
1911 & 829,0 & 1927 & 592,1 & 1943 & 402,8 \\
1912 & 641,8 & 1928 & 473,3 & 1944 & 787,2 \\
1913 & 585,0 & 1929 & 881,5 & 1945 & 710,1 \\
1914 & 910,2 & 1930 & 396,3 & 1946 & 632,6 \\
1915 & 158,9 & 1931 & 714,8 & 1947 & 977,5 \\
1916 & 779,8 & 1932 & 568,4 & 1948 & 714,9 \\
1917 & 808,5 & 1933 & 595,1 & 1949 & 740,0 \\
1918 & 595,0 & 1934 & 818,7 & 1950 & 538,1 \\
1919 & 440,0 & 1935 & 696,2 & 1951 & 523,4 \\
1920 & 736,0 & 1936 & 546,4 & 1952 & 491,4 \\
1921 & 869,7 & 1937 & 746,0 & 1953 & 486,6 \\
1922 & 727,8 & 1938 & 524,6 & 1954 & 552,2 \\
1923 & 655,6 & 1939 & 797,6 & 1955 & 476,8 \\
1924 & 1299,2 & 1940 & 1202,0 & 1956 & 607,5 \\
1925 & 598,7 & 1941 & 663,2 & 1957 & 637,9 \\
\hline
\end{tabular}

QUADRO N. ${ }^{\circ} 1$ 


\section{RESULTADOS OBTIDOS E CONCLUSÕES}

A análise da variância dos dados consta do Quadro n. ${ }^{0} 2$.

ANÁLISE DA VARIÂNCIA

\begin{tabular}{|c|c|c|c|}
\hline Causa de Variação & $\begin{array}{l}\text { Grau de } \\
\text { Liberdade }\end{array}$ & $\begin{array}{l}\text { Somas de } \\
\text { Quadrados }\end{array}$ & $\begin{array}{l}\text { Quadrados } \\
\text { Médios }\end{array}$ \\
\hline Regressão linear & 1 & $64.950,2$ & $64.950,2$ \\
\hline Regressão quadrática & 1 & $35.901,6$ & $35.901,6$ \\
\hline Regressão cúbica & 1 & $13.110,2$ & $13.110,2$ \\
\hline Regressão do $4 .^{\circ}$ grau & 1 & $4.385,0$ & $4.385,0$ \\
\hline Resíduo & 43 & $1866.396,4$ & $43.404,6$ \\
\hline
\end{tabular}

QUADRO N. 2

Verifica-se logo que os quadrados médios referentes às componentes do segundo ao quarto grau são menores do que o quadrado médio residual.

Para a componente linear acontece o contrário, mas não há o menor indício de significância estatística.

Conclui-se, pois, que se pode aceitar como inexistente qualquer tendência secular, do primeiro ao quarto grau, para a queda de chuvas em Pesqueira no período de 1910 a 1957, isto é, a tendência de decréscimo das precipitações aquosas, que alguns já têm sugerido para o Nordeste, não se manifesta absolutamente.

A média pluviométrica dêsses 49 anos foi de $679,0 \pm 29,7 \mathrm{~mm}$, onde 29,7 é o êrro padrão da média.

A distribuição das quedas anuais de chuvas de Pesqueira se pode aceitar como normal com média 679,0 e desvio padrão $205,5 \mathrm{~mm}$, com um coeficiente de variação de $30,3 \%$. Tal distribuiçảo inclui com $95 \%$ de probabilidade chuvas entre 263,9 e $1094,1 \mathrm{~mm}$.

A título de comparação com um clima de precipitação aquosa anual menos incerta, digamos que cálculos análogos feitos por GODOY e outros, pará Campinas (SP), indicaram média em 67 anos de observação de $1.382,8 \mathrm{~mm}$, com desvio 
padrão $258,9 \mathrm{~mm}$ e coeficiente de variação $18,7 \%$. Neste caso o nível de $95 \%$ de probabilidade abrangeria precipitações de 865,0 a $1900,6 \mathrm{~mm}$.

\section{ABSTRACT}

The authors studied the rainfall in Pesqueira (Pernambuco, Brasil) in a period of 48 years (1910 through 1957) by the method of orthogonal polynomials, degrees up to the fourth having been tried. None of them was significant, so that it seems that no trend is present.

The mean observed was $679.00 \mathrm{~mm}$., with standard error of the mean $205.5 \mathrm{~mm}$., and a $30.3 \%$ coefficient of variation.

The $95 \%$ level of probability would include annual rainfall from 263.9 up to $1094.1 \mathrm{~mm}$.

\section{BIBLIOGRAFIA CONSULTADA}

1 - FREITAS, MOACYR BRITTO DE, 1951 - Anais da Terceira Reuniáo Brasileira de Ciência do Solo, 2.0 tomo, pp. 843-914.

2 - GODOY HERNANI, IZAIAS RANGEL NOGUEIRA \& FREDERICO PIMENTEL GOMES, 1959 - Estudo sôbre a queda de chuvas em Campinas (em publicação).

3 - PIMENTEL GOMES, F., 1958 - Curso de Estatística Experimental, 133 pp. Piracicaba. 